\title{
Deliberative Forms of Democracy and Intergenerational Sustainability Dilemma
}

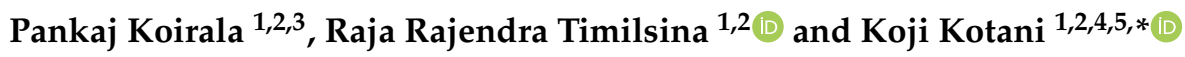 \\ 1 School of Economics and Management, Kochi University of Technology, Kochi 782-8502, Japan; \\ pankaj.koirala4@gmail.com (P.K.); timilsinaraja@gmail.com (R.R.T.) \\ 2 Research Institute for Future Design, Kochi University of Technology, Kochi 782-8502, Japan \\ 3 Institute for Integrated Development Studies, Kathmandu 44600, Nepal \\ 4 Urban Institute, Kyusyu University, Fukuoka 819-0395, Japan \\ 5 College of Business, Rikkyo University, Tokyo 171-8501, Japan \\ * Correspondence: kojikotani757@gmail.com
}

Citation: Koirala, P.; Timilsina, R.R.; Kotani, K. Deliberative Forms of Democracy and Intergenerational Sustainability Dilemma. Sustainability 2021, 13, 7377. https://doi.org/ $10.3390 /$ su13137377

Academic Editor: Marc A. Rosen

Received: 22 February 2021

Accepted: 25 June 2021

Published: 1 July 2021

Publisher's Note: MDPI stays neutral with regard to jurisdictional claims in published maps and institutional affiliations.

Copyright: (c) 2021 by the authors. Licensee MDPI, Basel, Switzerland. This article is an open access article distributed under the terms and conditions of the Creative Commons Attribution (CC BY) license (https:// creativecommons.org/licenses/by/ $4.0 /)$.

\begin{abstract}
Intergenerational sustainability (IS) has emerged as the most serious social problem reflecting climate change and accumulation of public debt in modern democratic societies, undermining the potential interests and concerns of future generations. However, little is known about whether or not deliberative forms of democracy with majority voting help support at maintaining IS by representing future generations' potential interests and concerns. We institute IS dilemma game with three forms of decision-making models with majority voting and examine how they maintain IS in laboratory experiments. In the IS dilemma game, a sequence of six generations is prepared where each generation consisting of three subjects is asked to choose either maintaining IS (sustainable option) or maximizing their own generation's payoff by irreversibly costing the subsequent generations (unsustainable option) with anonymous voting systems: (1) majority voting (MV), (2) deliberative majority voting (DMV) and (3) majority voting with deliberative accountability (MVDA). In MV and DMV, generations vote for their choices without and with deliberation, respectively. In MVDA, generations are asked to be possibly accountable for their choices to the subsequent generations during deliberation, and then vote. Our analysis shows that a decision-making model with only majority voting generally does not address IS, while DMV and MVDA treatments induce more and much more generations to choose a sustainable option than MV, respectively. Overall, the results demonstrate that deliberation and accountability along with majority voting shall be necessary in models of decision-making at resolving IS problems and representing future generations' potential interests and concerns.
\end{abstract}

Keywords: democracy; decision; majority voting; deliberation; intergenerational accountability; intergenerational sustainability; experimental research; future generations; representation

\section{Introduction}

People generally consider democracy to be a better option than some authoritarian system, and believe that it represents people, their interests and concerns [1-3]. With this belief, contemporary societies have adopted democracy and succeeded in achieving various economic, social and political objectives, such as poverty reduction, job creation, education, and improvements in health-care facilities. However, modern democratic societies face intergenerational sustainability (IS) problems, such as climate change, resource sustainability, public debt accumulation and environmental pollution, and these problems are reported to affect future generations' welfare [4-9]. IS problems arise when the current generation fails to consider the interests and concerns of future generations into their decision-making processes under a democratic system $[5,10,11]$.

The literature reports that some features of democracy, such as election cycles, the dominance of political interests, and the existence of some myopic voters, develop short-term 
tendencies (or presentism) in people's attitudes and behaviors, inducing the current generation not to consider future generations [10-15]. The short-term tendencies in democracy are exacerbated, especially when people become autonomous and alienated from societies with limited social interactions, making themselves myopic [15-17]. There are uprising voices and demands to address IS problems so that future generations' welfare, concerns, and voices should be reflected in the current practices of democracy $[8,18,19]$. Public protests around Greta Thunberg can be considered such an example for future generations' voices in relation to climate change [19].

Representation of future generations' voices in decision-making processes is claimed to be challenging under a democratic system [14,20-25]. In numerous democratic countries, children and/or women are not permitted to vote in elections, and it highlights that underrepresentation of some groups other than future generations emerges as a general social problem. Such an underrepresentation problem is present in IS problems, such as climate change, where future generations cannot participate in the current decision-making processes as they are yet to be born $[11,26]$. It affirms that a democratic system may need some new devices, innovations, reforms or transformations for addressing the underrepresentation as not only social, but also IS problems [5,23,27-29]. A group of scholars have argued that deliberative forms of democracy can influence the current generation to consider future generations and their potential interests and concerns, possibly inducing them to be more sustainable or future-oriented [11,30]. However, little is known about how deliberative forms of democracy with voting can resolve IS problems and represent future generations' potential interests and concerns.

We seek to experimentally examine and clarify how two deliberative forms of democracy with majority voting enhance IS as compared to majority voting without deliberation. One of the specific IS problems is described by "intergenerational sustainability dilemma" (IS dilemma), which is a situation where the current generation chooses to maximize (or sacrifice) its own benefits without (or for) considering future generations, compromising (or maintaining) IS [26,31,32]. Thus, we institute the IS dilemma game with three forms of decision-making models with majority voting by manipulating pre-voting components, and examine how they maintain IS in laboratory experiments. In the IS dilemma game, a sequence of six generations is prepared where each generation consisting of three subjects is asked to choose either maintaining IS (sustainable option) or maximizing their own generation's payoff by irreversibly costing the subsequent generations (unsustainable option) with anonymous voting systems: (1) majority voting (MV), (2) deliberative majority voting (DMV) and (3) majority voting with deliberative accountability (MVDA). In MV and DMV, generations vote for their choices without and with deliberation, respectively. In MVDA, generations are asked to be possibly accountable for their choices to the subsequent generations during deliberation, and then vote.

In our experiments, 312 subjects were employed from the student subject pool of Kochi University of Technology (KUT) and we randomly assigned each of the treatments to a group of subjects. We use the laboratory experiments with student subjects, because conducting laboratory experiments with KUT student subjects is cost-effective and student subjects are relatively uniform regarding their abilities, age, and so on. By employing students as subjects, some confounding factors are avoided to test experimental treatment effects [33-36]. The results show that the decision-making model with only majority voting generally does not address IS, while deliberation (DMV) and accountability (MADA) treatments induce more and more generations to choose a sustainable option than majority voting (MV), respectively. Overall, this study contributes to the literature by demonstrating that deliberation and accountability shall be necessary in decision-making models with majority voting at resolving IS problems. The message can be considered important when democratic countries and societies seek to address intergenerational fairness and/or justice along with an underrepresentation problem of future generations, as argued by Caney [8].

The remainder of this paper is structured as follows. Section 2 reviews the literature and discusses a theoretical link between democracy and IS, posing two specific hypotheses. 
We subsequently explain the experiments in Section 3. In Section 4, we report the analysis and results. Finally, Section 5 provides the discussion and conclusion along with some suggestions for future research.

\section{Theoretical Section}

The concept of democracy is too broad to cover in the limited space of a single study and there exists numerous definitions of democracy [1,37-40]. For example, May [37] defines "democracy as a responsive rule qua necessary correspondence between acts of governance and the desires with respect to those acts of the persons who are affected". Przeworski et al. [1] defines democracy as a form of rules, and Dahl [39] refers to democracy as actual governments that meet the following criteria: effective participation, voting equality, enlightened understanding, agenda control, and inclusion of adults. Regardless of the aforementioned variations, it appears to take two main forms: (i) direct democracy and (ii) representative democracy. Direct democracy allows people to equally and directly participate in the decision-making process, such as discussion, voting, or other acts of politics, and the examples include electronic, participatory, and/or deliberative forms of democracy $[1,23,41,42]$. Representative democracy allows people to participate indirectly in the decision process and choose the representatives that make decisions on behalf of them. The examples include parliamentary and presidential forms of democracy $[1,40]$. This study focuses on deliberative forms of democracy with voting in a class of direct democracy, considering that it is the first step to analyze their effects on human behaviors in IS under laboratory settings.

Several scholars have attempted to characterize democracy through models of decision-making [43-45]. The model of decision-making is defined as a function which takes the votes (or choices) as input from the members in a group or society, delivering a collective decision as output [46]. The model of decision-making is claimed to consist of two components (i.e., components of models of decision-making): (1) pre-voting component-a prior environment for people to engage, communicate and discuss socially on the common concerns, issues and agendas; and (2) voting component - a rule that aggregates individual independent choices to a collective decision [16,43,46,47]. Deliberation and voting are regarded as components of the decision-making models, and majority voting is widely adopted [41]. The literature suggests two main models of deliberative decisionmaking: a pure deliberation model where participants deliberate and reach (or aim to reach) consensus for a collective decision without individual voting; and a mixed model of deliberation where participants deliberate and make a collective decision through individual voting $[16,17,43,46]$. Some theories suggest that deliberation (i.e., pure deliberation model) can play the following roles: (i) it enhances responsiveness to the people, groups, and agendas [41]; (ii) it connects people's preferences to a collective will by potentially generating epistemic and ethical goods through their reasons and arguments [48-50]; and (iii) it helps to make a collective decision by agreements and commitments to the decision [3,11,18,51-56]. Warren [41] argues that deliberation is weak to be able to represent some groups, such as young and ethnic groups, suggesting that some supplementary or complementary components, such as voting, may be necessary.

Past literature has examined the influence of the mixed model (i.e., deliberation is supplemented by individual voting) on human behaviors and the problem of underrepresentation for some groups by conducting surveys or controlled experiments [20,22,57-62]. Luskin et al. [63] conduct deliberative polls in UK and find that deliberation affects public preferences on some policies. List et al. [17] find that the deliberation before voting brings a higher proximate single-peakedness in voters' preferences than the majority voting only utilizing deliberative polls data. In experimental studies, for example, Simon and Sulkin [64] analyze the role of deliberation, concluding that deliberation enhances equitable outcomes for intra-generational members. Goeree and Yariv [58] experimentally evaluate the effects of deliberation under various decision-making rules and demonstrate that it improves the efficiency of institutional decisions. Persson et al. [65] analyze people's behaviors 
through field experiments and find that deliberation with voting increases the perceived legitimacy of democratic procedures compared to non-voting. Ideally, deliberative forms of democracy should come with active participation of stakeholders, and it may be necessary to include possible underrepresented groups in a decision-making process [66]. Stoiciu and Gherghina [25] analyze the role of deliberation for underrepresentation problems, finding that it promotes inclusion of opinions from women, various social strata, and ethnic and other minorities $[67,68]$. However, another group of studies points out that deliberation may not be sufficient to resolve underrepresentation of some groups, especially young and uneducated people [20,22,59-62,69-71]. Specifically, Caluwaerts and Reuchamps [67] and Harris [68] discuss and highlight the importance of representing children, young people, and future generations in deliberation, arguing that some mechanisms, such as citizens' assemblies, are necessary not only for developing a future-oriented democracy, but also for determining its legitimacy.

In the context of IS problems, future generations tend to be underrepresented in collective decision-making $[11,14,19]$. The difficulty arises because future generations can neither communicate nor represent their voices with the current generation, especially when they do not have overlapping life time. For instance, climate change problems shall adversely affect future generations that are not born yet; however, such unborn future generations do not have any means to convey what they want to the current generation in the decision-making process. Several researchers have empirically and experimentally studied IS problems, employing some decision-making models of deliberation and/or voting [3,19,72-82]. Gronlund et al. [22] compare people's knowledge and opinions on long-run energy politics under traditional face-to-face and online deliberation, suggesting that both settings only enhance people's knowledge. Setala et al. [73] conduct pre-post surveys and deliberation on people's knowledge for the use of nuclear power plants, finding that deliberation promotes their knowledge than without deliberation. Himmelroos and Christensen [74] examine public opinions on the use of nuclear power plants through conducting quasi-experiments, demonstrating that deliberation with high-quality arguments brings people's opinion changes. Hauser et al. [75] analyze group behaviors for IS by conducting intergenerational goods games and suggest that voting reduces the exploitation of resources by restraining defectors. MacKenzie and Caluwaerts [3] conduct online experiments and analyze group decisions for climate policies, showing that deliberation induces groups to support the policies.

Another group of studies focuses on how IS dilemma can be resolved by deliberation or some institutions to represent future generations through conducting laboratory and/or field experiments with IS dilemma game under non-overlapping generation settings. Kamijo et al. [31] conduct laboratory experiments with a student subject pool and show that introduction of a imaginary future generation (IFG) who are assigned to represent future generations in deliberation enhances IS. Shahrier et al. [32] and Timilsina et al. [83] conduct field experiments using a subject pool of the general public in urban and rural areas of Bangladesh and Nepal, respectively, and show that rural people choose sustainable options much more often than do urban ones. Shahrier et al. [84] further conduct field experiments in Bangladesh with subjects of urban people, demonstrating that future ahead and back mechanism (FAB that asks people to take the standpoint of future generations and to think about their requests to the current generation) induces people to choose sustainable options. Timilsina et al. [85] conduct field experiments with a subject pool of general people in Nepal and conclude that intergenerational accountability (IA that asks people to be accountable for their decisions to future generations) is effective at maintaining IS. Katsuki and Hizen [81] address people's behaviors under some voting rules in laboratory settings, finding that they fail in enhancing IS. Overall, these studies demonstrate that some attempts and institutions (with deliberation), such as IFG, FAB and IA, shall be able to address underrepresentation of future generations, and also maintain IS.

In political science, accountability refers to a responsibility of decision-makers on behalf of people spanning the obligations to report, explain, and answer for the resulting conse- 
quences where people can sanction (or reward) the decision-makers [1]. Accountability holds when decision-makers and receivers are engaged in two-way communication, and it is established that people become fair and/or just when they are accountable for their decisions $[86,87]$. In the context of IS problems, such two-way communication between the current and future generations is not always possible, especially in the long-run perspective of non-overlapping generations [26], and the only possible communication path is unidirectional, or one-way communication from the current to future generations. Given this state of affairs, this research suggests IA mechanism along with deliberation in which people in the current generation are asked to be accountable for their decisions and leave their written reasons and advice to future generations, hypothesizing that IA brings fair and sustainable decisions in the current generation for IS.

In some real-life decision-making contexts, societies deliberate and conclude with majority voting on some salient and/or long-term problems, such as Brexit (in UK) and other instances. For examples, countries (e.g., Ireland and Iceland), political parties (e.g., Alternativet Party of Denmark, Czech Pirate Party of Czech and Demos Party of Romania), country representatives (e.g., UN), and officials follow deliberation and/or voting for making decisions whose influence affect future generations in the long run $[23,60,88-90]$. In summary, not only the literature, but also real-world social movements reveal that underrepresentation of future generations is considered a fundamental problem for democracy and IS $[3,11,67,68]$.

In democratic systems, voting is widely adopted and considered the most legitimate mechanism [37,41]. However, some of its features are known to develop short-term tendencies in people's attitudes and behaviors, compromising IS [10-15]. The literature argues that people become autonomous and alienated from the societies when deliberative opportunities are scarce, making themselves myopic [15-17,68]. Drawing on literature, deliberation among people (i.e., intragenerational) before voting is hypothesized to prevent people from taking myopic behaviors, enhancing IS [3,11,18,41,51,53-55]. On the other hand, the effect of deliberation is claimed to be unstable in some situations where people engage less and just end the deliberation process $[3,46,55]$. Given this, we consider that IA induces people to engage more on deliberation, because introduction of accountability is known to bring a responsibility of decision-makers, enhancing IS, as argued earlier [1,85-87,91,92]. Based on the above arguments, the hypotheses in our experiments are posed as follows:

Hypothesis 1. Intragenerational deliberation and individual voting (i.e., DMV) results in higher IS than only with individual voting (i.e., $M V$ ).

Hypothesis 2. Intragenerational deliberation with intergenerational accountability and individual voting (i.e., MVDA) results in higher IS than only with intragenerational deliberation and individual voting (i.e., DMV).

To test the two hypotheses, we empirically compare and characterize the probabilities for generations to choose a sustainable option across three models of decision-making, that is, MVDA, DMV, and MV, including other control variables (SVO, sociodemographic factors, and others) that will be discussed in the subsequent section. One important measurement is the probability for generations to choose a sustainable option, and it is considered a good approximation of IS. Because IS increases in the probabilities, the two hypotheses follow that probabilities for generations to choose a sustainable option are the highest in MVDA, the second in DMV, and the last in MV, respectively.

From a game theoretical view, choosing an unsustainable option is a Nash equilibrium (NE) strategy, as well as a dominant strategy for each generation in the IS dilemma game, because it maximizes their own payoff, irrespective of how other generations chose in the past and will choose in the future within the same sequence. On the other hand, all allocations in the IS dilemma game are Pareto-optimal in the sense that every allocation cannot be Pareto-improved by any other feasible allocation. For example, when every generation keeps choosing an unsustainable option, the resulting allocation is still con- 
sidered Pareto-optimal. These features of the IS dilemma game arise from the fact that the current generation unidirectionally affects future generations, representing how it is challenging to maintain sustainability $[15,31,32,81]$. There exists a unique allocation that leads to sustainability and maximizes the sum of payoffs for all the generations (i.e., social welfare) in the IS dilemma game. When every generation keeps choosing a sustainable option, the resulting allocation shall be considered socially desirable by not only maintaining sustainability, but also maximizing the sum of payoffs for all generations. The theoretical prediction suggests that people choose an unsustainable option and fail to maintain IS under the IS dilemma game in any model of decision-making. However, some behavioral and experimental studies in economics establish that people do not always follow NEs and dominant strategies in some situations [93-99].

\section{Experimental Design}

\subsection{Experimental Setup}

We conducted laboratory experiments by following the IS dilemma game, a social value orientation (SVO) game and questionnaire surveys for each subject's critical thinking disposition, empathic concern, and sociodemographic information. Experiments were carried out in the laboratory of the Kochi University of Technology (KUT) with a total of 312 Japanese students, including 145 females and 167 males, aged between 18 and 23. The subjects were recruited from the student subject pool of KUT with various specializations, such as economics, engineering, management, and natural sciences. We used the laboratory experiments with student subjects due to the following reasons: (i) conducting laboratory experiments with KUT student subjects is cost-effective under our research budget and time constraints [100-102], and (ii) university student subjects are homogeneous with respect to cognitive abilities, age, and other sociodemographics, and some confounding factors are avoided to test experimental treatment effects [33-36]. Since our experiments were carefully designed to minimize the confounding factors, it is our belief that the directions and magnitudes of the treatments' effects from our laboratory experiments are reliable for external validity to a certain extent, as argued in Levitt and List [33] and Falk and Heckman [36]. At the same time, it shall be desirable to conduct some follow-up field or social experiments with subjects of the general public to rigorously establish the external validity in future.

\subsubsection{Intergenerational Sustainability Dilemma Game}

We implement the IS dilemma game following the laboratory and field experiments of Kamijo et al. [31] and Shahrier et al. [32]. Building upon previous IS dilemma game experiments, we add a new element of individual voting mechanism to the experimental design, the details of which are discussed later in this section. IS dilemma game consists of a sequence of six generations. A "generation" is a group of three members, while in a "sequence", six chronologically arranged generations share the same resource $(X)$ one after another. In IS dilemma game, each generation is asked either to maintain intergenerational sustainability (IS) by choosing option $B$ (sustainable option) or to maximize their own generation's payoff by choosing option $A$, imposing an irreversible cost to the subsequent generations (unsustainable option). By choosing option $A$, each generation receives a share of $X$. On the other hand, the generation receives a share of $X-900$ by choosing option $B$.

We randomly assign each generation to the first, second, ... and sixth generations, respectively. The current generation's decision affects the subsequent generations such that subsequent generations' shares decline irreversibly and uniformly by 900 when the current generation chooses option $A$, otherwise not. For instance, suppose that $X=3600$ and the first generation chooses option $A$. Then, the second generation will face a game in which they receive 2700 and 1800 for choosing options $A$ and $B$, respectively. However, if the first generation chooses option $B$, the second generation faces the same decision environment as that of the first generation faces. That is, when the first generation chooses option $B$, the second generation faces the game receiving 3600 and 2700 by choosing options $A$ and $B$, 
respectively. Following the same rules, the game continues for the subsequent generations (i.e., between $i$ th and $i+1$ th generations) in a sequence. Hence, option $B$ can be considered the "sustainable option", whereas option $A$ is the choice that compromises IS and can be considered as the "unsustainable option."

In the experiments, the first generation starts the game with a share of $X=3600$ experimental points, by choosing option $A$, the generation earns 3600 points, where by choosing option $B$, the generation earns 2700 points. Consequently, members of this generation split the points equally among themselves and each member earns 1200 points by choosing option $A$, and 900 points by choosing option $B$ as a generation share, respectively. The IS dilemma game experiment is designed in a way that the fifth and sixth generations possibly face the situation in which options $A$ and $B$ are associated with zero and negative shares, respectively. When the generations from the first to the fourth choose option $A$, then the fifth generation will face the game in which they receive generation shares of zero points and -900 points by choosing options $A$ and $B$, respectively. If the generation's share is negative, say, $-Z$, each generation member will receive the equal points of $-Z / 3$. When the subjects receive negative points, each of them needs to refund $Z / 3$ points to the experimenter. In such situations, the points of $Z / 3$ are deducted from each member's participation fee of 600 points so that the individual payoff at least becomes nonnegative (see Supplementary Materials).

As shown in figure 1, we prepare three treatments namely, (1) majority voting (MV), (2) deliberative majority voting (DMV) and (3) majority voting with deliberative accountability (MVDA) that are as follows:

- $\quad$ MV (base group treatment): Three members in a generation are asked to cast their anonymous and independent votes for option $A$ or option $B$. The members in a generation see the faces of each other, but they are not allowed to communicate before they vote. After each member's voting, the generation decision between options $A$ and $B$ is made by majority rule. Specifically, the majority rule means that the generation decision is made as $A$ (or $B$ ) if two or all three members vote for option $A$ (or option B).

- DMV: Three members in a generation are asked to deliberate over choosing between options $A$ and $B$ up to $10 \mathrm{~min}$ before they vote. After that, the members cast their anonymous and independent votes for option $A$ or option $B$. The generation decision is made by majority rule as in MV.

- MVDA: Three members in a generation are asked to deliberate and collectively provide reasons and advice for their possible generation decision to the subsequent generations over choosing between options $A$ and $B$ up to $10 \mathrm{~min}$. When the generations are not the 1st one, they receive reasons and advice from the previous generation(s) before deliberation. After that, the members cast their anonymous and independent votes for option $A$ or option $B$. The generation decision is made by majority rule as in MV and DMV. 


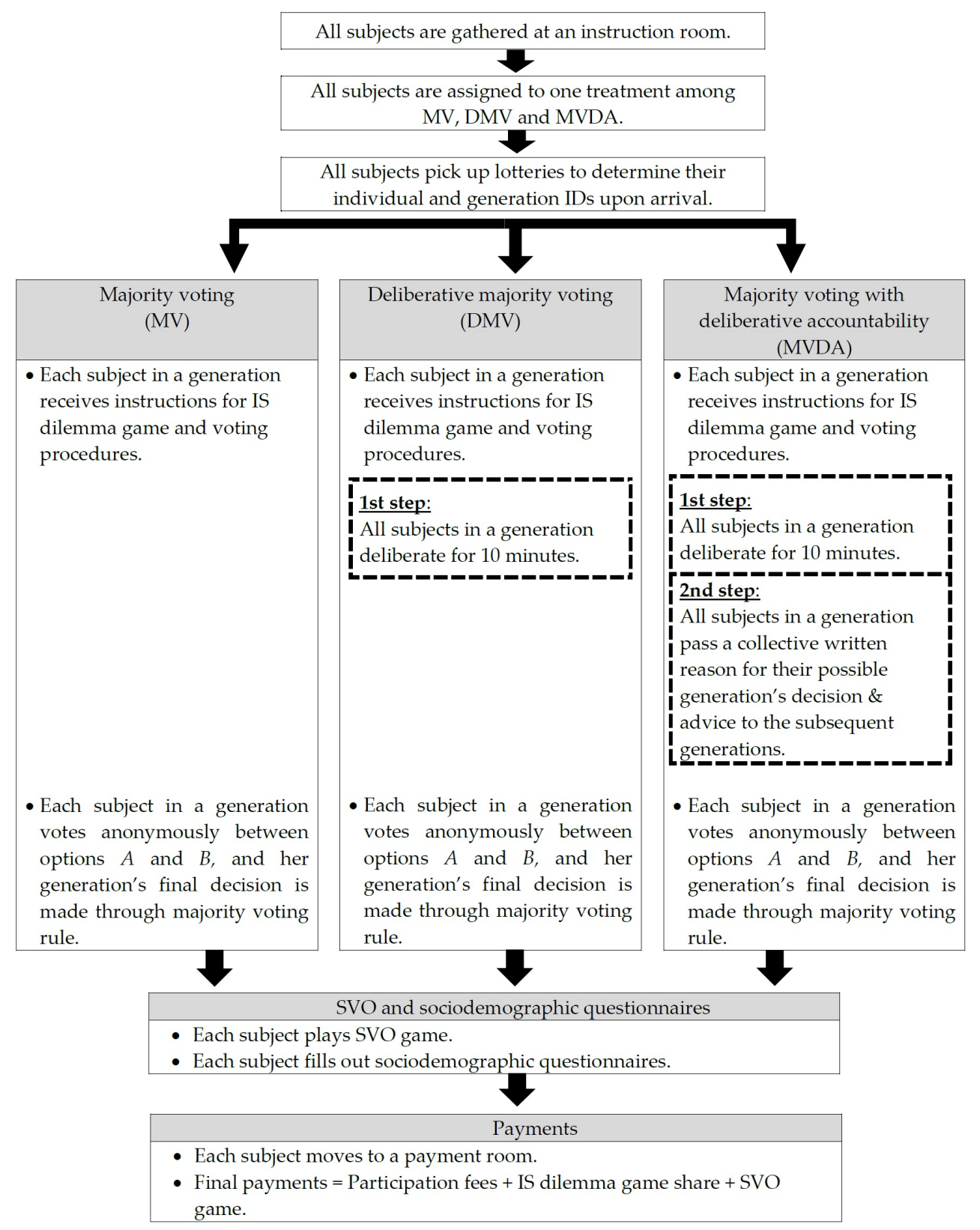

Figure 1. A flow chart of procedures for a subject to participate in the experiment.

\subsubsection{Social Value Orientation (SVO) and Psychological Factors}

We use the "slider method" to identify the subjects' social preferences by understanding their social value orientation (SVO) [103]. SVOs are already well-established to be stable for a long time (see, for example, Van Lange et al. [104] and Brosig-Koch et al. [105]). The slider method consists of 6 items where each subject is asked to share an amount of money or points with another subject. Each item consists of nine pairs of distributions for self and the other. The average allocation of oneself $\overline{A_{s}}$ and average allocation for the $\overline{A_{o}}$ are computed from all 6 items. Then, 50 is subtracted from $\overline{A_{s}}$ and $\overline{A_{o}}$ to shift the base of the resulting angle to the center of the circle $(50,50)$. The index of a subject's $\mathrm{SVO}$ is given by $\mathrm{SVO}=\arctan \frac{\left(\overline{A_{s}}-50\right)}{\left(\overline{A_{0}}-50\right)}$. We combine "altruist $\left(\mathrm{SVO}>57.15^{\circ}\right)^{\prime \prime}$ and "prosocial $\left(22.45^{\circ}<\mathrm{SVO}<57.15^{\circ}\right)$ " types into a single category of "prosocial"; "individualist $\left(-12.04^{\circ}<\mathrm{SVO}<22.45^{\circ}\right)$ " and "competitive (SVO $\left.<-12.04^{\circ}\right)^{\prime \prime}$ to "proself" as it is often done in psychology research for presenting results in a simple way. The subjects are informed in detail that their total payoffs from the SVO game are dictated by their own and anonymous pair's choices. The subjects are instructed about the game rules, points and 
total payoffs they receive from the game. The subjects perform the SVO tasks individually and submit their sheets to research assistants (RAs). RAs calculate the total payoff by randomly matching between the subjects from the same day's session.

\subsection{Experimental Procedures}

The first author administered the experiments with research assistants (RAs). One session comprises the IS dilemma game, SVO, sociodemographic questionnaires and payments. For each session, 18 subjects ( $=6$ generations) were gathered at an instruction room, and one treatment among MV, DMV, and MVDA was randomly assigned (Figure 2). We announced that no communications were allowed without any permission. Then, the 18 subjects read and watched written and video instructions for IS dilemma game. We also made an oral presentation, conducting Q\&A and quizzes for double-checking subjects' understanding. Unless the subjects correctly answered, we did not proceed to the IS dilemma game. At the beginning of the IS dilemma game, each subject drew a chip from a bag to determine his/her sequence $(i)$, generation $(j)$ and individual IDs $(k)$. Each chip displays a letter (e.g., $P, Q, R$ ) corresponds to $i \cdot j-k$ (Figure 2). In each session, the $i$ takes one letter out of three from $\{P, Q, R\}$ and $j$ takes one number out of $\left\{j^{\prime}, j^{\prime}+1\right\}$ for $j^{\prime}=\{1,3,5\}$ (e.g., $j=\{1,2\}$ when $j^{\prime}=1 ; j=\{3,4\}$ when $j^{\prime}=3$ ). In Figure 2, for example, $P 1$ and $P 2$ corresponds to $j^{\prime}$ and $j^{\prime}+1$ when $j^{\prime}=1$ for the sequence $i=P$. The $k$ takes one number out of $\{1,2,3\}$ as an individual ID in a generation. The subjects whose generation IDs belong to a class of $i \cdot j^{\prime}$ (e.g., $P 1, Q 1, R 1$ ) first moved to different game rooms and went through IS dilemma game. Those with $i \cdot j^{\prime}+1$ (e.g., $\left.P 2, Q 2, R 2\right)$ stayed in the instruction room and filled out SVO and questionnaires, while waiting. Second, the subjects with $i \cdot j^{\prime}+1$ moved to the game rooms and went through the IS dilemma game as the next generation, after confirming that the subjects with $i \cdot j^{\prime}$ finished and were ready to get back to the instruction room to complete the SVO and questionnaires. In this step, we were careful about the routes and logistics such that the subjects with $i \cdot j^{\prime}+1$ neither met those with $i \cdot j^{\prime}$ nor found which room each subject in the previous generation was in.

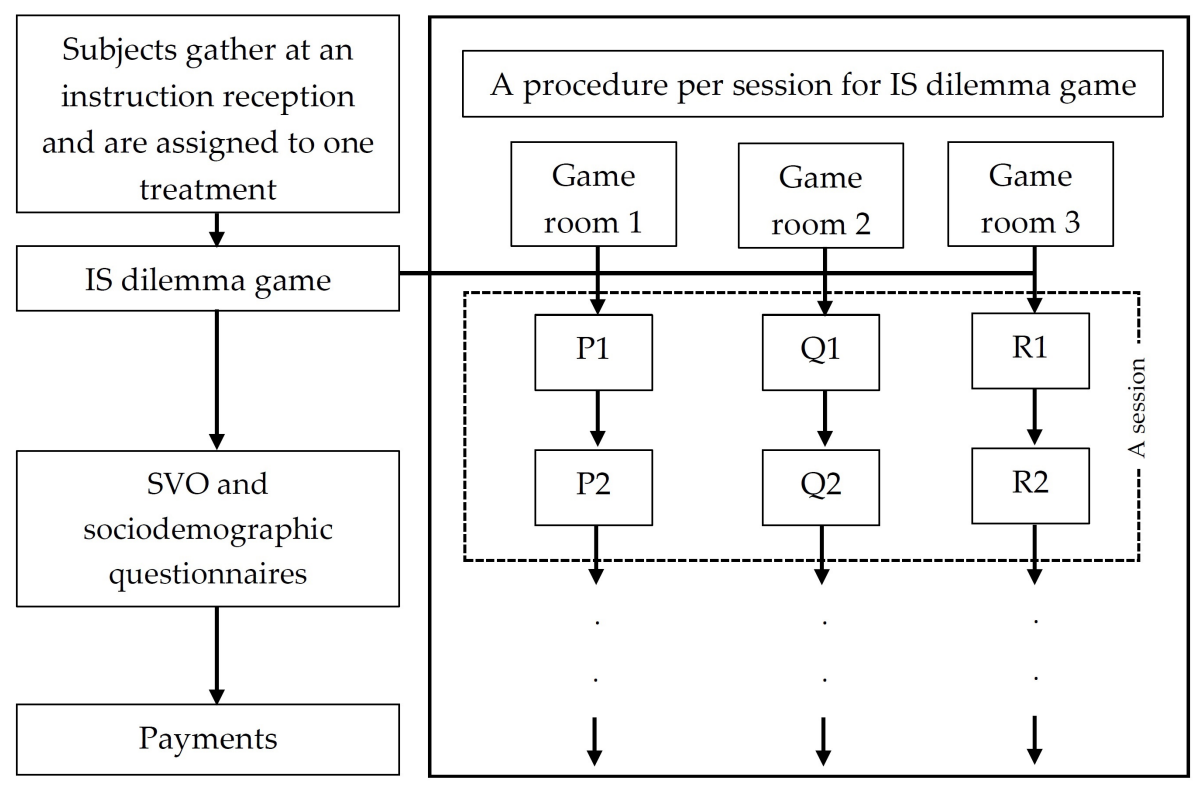

Figure 2. A flow-chart of the procedures for one session.

One RA was present in each game room, and three subjects in a generation were guided to take their respective independent seat according to the individual IDs and to check their understanding about the pre-voting procedures per treatment (see Figure 1 for the detailed procedures per treatment). The members were also guided to observe the previous generations' decisions and their payoffs between options $A$ and $B$ on a white board in the room. When subjects were in the 1st generation, the RA told them that they 
did not have any previous generation. After confirming the understanding and situations associated with payoffs in IS dilemma game, subjects went through all the procedures per treatment under the RA's support, and each subject anonymously and independently voted for option $A$ or option $B$. The RA counted their votes, announcing the generation decision by majority voting rule in each room. The three subjects recorded their individual and generation decisions and returned to the instruction room, finalizing the remaining tasks, such as SVO and sociodemographic questionnaires. Finally, the subjects received their payments with some exchange rates according to their decisions. The payment for each subject was calculated as a summation of his/her earnings from the (i) participation fee, (ii) the IS dilemma game with 1 point $=2 \mathrm{JPY}$ and (iii) the SVO game with 1 point $=1 \mathrm{JPY}$ where each subject receives, on average, $300 \mathrm{JPY}, 1970 \mathrm{JPY}$ and $900 \mathrm{JPY}$, respectively. In total, 17 sessions were completed and 312 subjects (or 104 generations) participated, where one session was conducted with 24 subjects.

\section{Results}

Table 1 presents the definitions and descriptions of sociodemographic and psychometric variables used in the analyses. A total of 312 (104) subjects (generations) participate in the experiments with 105 (35), 99 (33) and 108 (36) in majority voting (i.e., MV), deliberative majority voting (i.e., DMV) and majority voting with deliberative accountability (i.e., MVDA) treatments, respectively (see Table S3 in Supplementary Materials). Similarly, $46.47 \%$ female subjects participate in the experiments, and the percentages are $51.42 \%$, $43.43 \%$ and $44.44 \%$ in MV, DMV, and MVDA treatments, respectively. These facts reflect that there is a proper gender balance across the treatments. The past literature establishes that gender affects attitudes and behaviors and might bring differences in preferences between males and females in some contexts of economic decision-making [106].

Table 1. Definitions and descriptions of the variables.

\begin{tabular}{ll}
\hline Variables & Definitions and Descriptions \\
\hline $\begin{array}{l}\text { Dependent variables } \\
\text { Choice } B\end{array}$ & A dummy variable that takes 1 if a generation chooses option $B$; otherwise, 0. \\
\hline
\end{tabular}

Independent variables

Treatment dummies (base group $=$ MV)

DMV A dummy variable that takes 1 if a generation is in DMV treatment; otherwise, 0.

MVDA

A dummy variable that takes 1 if a generation is in MVDA treatment; otherwise, 0 .

Sociodemographic and psychometric variables

Prosocial A number of members in a generation whose social value orientation is categorized as "prosocial".

Gender A number of female members in a generation.

Empathic concern Summation of a subject's empathic concern measured in 5-points Likert scale, ranging from 0 to 28 points.

Personal distress Summation of a subject's personal distress measured in 5-points Likert scale, ranging from 0 to 28 points.

Critical thinking disposition Summation of subject's critical thinking dispositional scale measured from 5-points Likert scale, ranging from 13 to 65 points.

Table 2 presents the frequencies and the percentages of generation choices between options $A$ and $B$ in IS dilemma game by treatments. As shown, only $2(5.71 \%)$ of the total 35 generations choose option $B$ in MV. Among the 33 generations, 4 (12.12\%) choose option $B$ in DMV. Of the total 36 generations, $10(27.78 \%)$ choose option $B$ in MVDA. The results show that generation choices of option $B$ are higher in DMV and MVDA than those in MV. To test whether the distributions of generation choices between options $A$ and $B$ are independent of the treatments, we perform chi-squared $\left(\chi^{2}\right)$ test by taking the following pairs: MV vs. DMV, MV vs. MVDA and DMV vs. MVDA, using the frequencies as 
summarized in Table 2. A null hypothesis is that the distribution of generation choices between options $A$ and $B$ are the same for each pair of treatments. The results reject the null hypothesis for MV vs. MVDA. However, we fail to reject the null hypotheses for MV vs. DMV and DMV vs. MVDA. Overall, the results confirm that the distributions of the generation choices between options $A$ and $B$ in MVDA are different from those in MV.

Table 2. The frequencies and percentages of generation choices between options $A$ and $B$ by treatments.

\begin{tabular}{ccccc}
\hline & \multicolumn{2}{c}{ Frequency and Percentage of Option $\boldsymbol{B}$ Choice } & \\
\cline { 2 - 4 } Choices $\boldsymbol{A}$ or $\boldsymbol{B}$ & MV (N = 35) & DMV (N = 33) & MVDA (N = 36) & Overall (N = 104) \\
\hline$A$ & $33(94.29 \%)$ & $29(87.88 \%)$ & $26(72.22 \%)$ & $88(84.62 \%)$ \\
$B$ & $2(5.71 \%)$ & $4(12.12 \%)$ & $10(27.78 \%)$ & $16(15.38 \%)$ \\
\hline Subtotal & $35(33.66 \%)$ & $33(31.73 \%)$ & $36(34.61 \%)$ & $104(100 \%)$ \\
\hline
\end{tabular}

Note: MV vs. DMV $\left(\chi^{2}=0.867, p=0.352\right)$, MV vs. MVDA $\left(\chi^{2}=6.151, p=0.013\right)$ and DMV vs. MVDA $\left(\chi^{2}=2.610, p=0.106\right)$.

For a robustness check, we apply the nonparametric test by considering the correlation among the observations of generation choices within a sequence. To this end, we cluster the generation choices at a sequence level. There is a total of 19 sequences, six each in MV and DMV, while there are seven in MVDA. We calculate the average for each sequence of generations that choose option $B$ and run the Mann-Whitney test to confirm the null hypotheses that the distributions of the averages for the sequences are the same in each pair of treatments. We find that the distributions of averages for the sequences of generations that choose option $B$ are different and significant at $1 \%$ for MV vs. DMV, MV vs. MVDA, and DMV vs. MVDA, respectively. Overall, the generations in DMV and MVDA appear to choose option $B$ more often than those in the MV treatment.

Finally, to characterize the effects of treatments on generation choices of option $B$, we run logit regression by taking generation choices between options $A$ and $B$ as the dependent variable that takes unity when a generation chooses option $B$, otherwise zero. The independent variables are the treatment dummies (DMV and MVDA), a number of prosocial members in a generation (prosocial), average critical thinking disposition, average empathic concern, and average personal distress and gender (a number of females in a generation). Since generation decisions are taken at the generational level, we take an average or a summation of independent variables for the analyses (see the definitions of independent variables in Table 1). We report the marginal effects of the treatment dummies and other independent variables from models 1 to 3 in Table 3. The marginal effects of the treatment dummies can be considered causal due to their random assignments [107]. In model 1, we present the marginal effects of the treatment dummies. In model 2, we add a number of prosocial individuals in a generation. Finally, in model 3, we further add other sociodemographic variables, such as gender, average critical thinking disposition, average empathic concern and average personal distress, for a robustness check.

Models 1, 2 and 3 in Table 3 show that the marginal effects of DMV on generation choices of option $B$ are economically and statistically significant ( $p=0.076$ ). They demonstrate that the generations in DMV have $7 \%$ higher probability of choosing option $B$ than those in MV, holding all other factors fixed. We also find that the marginal effects of MVDA on generation choices of option $B$ are economically and statistically significant $(p<0.01)$, reflecting that the generations in MVDA have $13.8 \%$ higher probability of choosing option $B$ than those in MV. In summary, deliberation and accountability (i.e., DMV and MVDA treatments) result in higher percentages of option $B$ choices than without deliberation (i.e., MV treatment). The results support Hypothesis 1, being consistent with the theories related to deliberation, such as "the theory of communicative actions", advocating that deliberation among the participants along with reasoning helps achieve better social outcomes [51]. 
Table 3. Marginal effects of independent variables on the probability of option $B$ choice in logit regressions (base group $=$ option $A$ choice).

\begin{tabular}{|c|c|c|c|}
\hline & \multicolumn{3}{|c|}{ Option B Choice } \\
\hline & Model 1 & Model 2 & Model 3 \\
\hline \multicolumn{4}{|l|}{ Independent variables } \\
\hline \multicolumn{4}{|c|}{ Treatment dummies (base group = MV) } \\
\hline DMV & $\begin{array}{l}0.064^{*} \\
(0.038)\end{array}$ & $\begin{array}{c}0.087^{* *} \\
(0.040)\end{array}$ & $\begin{array}{l}0.070 * \\
(0.040)\end{array}$ \\
\hline MVDA & $\begin{array}{c}0.221^{* * * *} \\
(0.042)\end{array}$ & $\begin{array}{c}0.140 * * * \\
(0.036)\end{array}$ & $\begin{array}{c}0.138^{* * *} \\
(0.036)\end{array}$ \\
\hline \multicolumn{4}{|c|}{ Sociodemographic and psychometric variables } \\
\hline Prosocial & & $\begin{array}{c}0.116^{* * *} \\
(0.016)\end{array}$ & $\begin{array}{c}0.112^{* * *} \\
(0.016)\end{array}$ \\
\hline Gender & & & $\begin{array}{l}-0.016 \\
(0.016)\end{array}$ \\
\hline Empathic concern & & & $\begin{array}{c}0.019 * * * \\
(0.006)\end{array}$ \\
\hline Personal distress & & & $\begin{array}{c}-0.016^{* *} \\
(0.007)\end{array}$ \\
\hline Critical thinking disposition & & & $\begin{array}{c}1.964 \times 10^{-4} \\
(0.006)\end{array}$ \\
\hline Observations (generations) & 104 & 104 & 104 \\
\hline
\end{tabular}

We conduct further analysis by running logit regressions to estimate the IA effect on generation choices of option $B$. For this, we take DMV treatment dummy as the base group, excluding the observations in MV. Our result shows that the generations in MVDA are 5\% more likely to choose option B than those in DMV (see Table S5 in Supplementary Materials). This result supports our Hypothesis 2 that intragenerational deliberation with intergenerational accountability (i.e., MVDA treatment) results in higher percentages in generation choices of option $B$ than does deliberation (i.e., DMV treatment). Note that generation members in MVDA need to deliberate about the reasons and advice for their possible decision between options $A$ and $B$. We realize that those who choose option $B$ have often written "we should not harm others", and /or "we feel bad to hurt others, therefore, we have chosen option B." as part of their reasons and advice. Such statements imply that IA might have influenced the generation members to be sympathetic with and/or take future generations' perspective, choosing option $B$. On the other hand, generations that choose option $A$ have typically written "we choose option A since it gives us more points", and "we should think about ourselves, not about others", reflecting their self-maximization motives. Overall, IA appears to function as a one-way communication device via receiving and giving reasons and advice over generations for maintaining IS in comparison with DMV treatment where such a communication opportunity is missing.

Models 2 and 3 in Table 3 show that a number of prosocial members per generation is economically and statistically significant $(p<0.01)$ (see also Table S4 in Supplementary Materials). The results demonstrate that the generations are $11.2 \%$ more likely to choose option $B$ with an increase in prosocial members per generation. The results are consistent with previous studies that find the positive influence of prosociality on people's behaviors for IS $[31,32,75,108,109]$. The result in Table 3 shows that the generations are $1.9 \%$ more likely to choose option $B$ when the average empathic concern of generation members increases by one additional point $(p<0.01)$. Our result is consistent with previous findings, showing that empathic concern induces people to value others' benefits [110-112]. The result shows that the generations are $1.6 \%$ less likely to choose option $B$ with an 
additional unit increase in average personal distress of a generation members, implying that personal distress might induce people to make more unsustainable choices [113].

\section{Discussion and Conclusions}

We institute ISDG with three forms of decision-making models by experimentally manipulating pre-voting components and examine how they maintain IS in laboratory experiments. Game theory predicts that generations will choose an unsustainable option in ISDG, and our results in the base group (MV) are in line with the prediction. Other two models of deliberative decision-making (i.e., DMV and MVDA) are found to be more effective than MV. We also find that a majority of generations still chooses an unsustainable option in all treatments. The results imply that maintaining IS shall be very challenging with majority voting, especially when generations are neither biologically nor socially connected, that is, non-overlapping generation. However, when deliberation and one-way communication (IA) from the current generation to future generations are introduced along with majority voting, generations choose to be sustainable.

Deliberative theories and the associated empirical studies reveal that the effect of deliberation is context-specific as argued before, and it is well-known that the deliberation effect can be either positive or negative to have a socially desirable outcome $[11,41,53,55,114,115]$. Delli Carpini et al. [55] summarize that deliberation can be ineffective or counterproductive in some situations. Game theory also predicts that a majority of people should choose an unsustainable option as suggested by NE and dominant strategies. These facts imply that IS dilemma game can be interpreted to be one specific situation where the deliberative form of democracy with voting does not have a huge positive effect on IS. The interpretation appears to reflect our results that the percentages of generations that choose a sustainable option in both deliberation treatments remain low.

We conjecture that people in MVDA treatment are engaged more seriously in deliberation than those in DMV treatment through being accountable (i.e., writing and leaving their reasons and advice to future generations, that is, IA mechanism), inducing people to choose a sustainable option. We raise the three possible channels: (i) warm-glow (or guilt aversion), (ii) legacy motive (as a cooperator), and (iii) moral commitment [10,11,116-118]. First, people in the current generation may feel warm-glow or guilt aversion by leaving nice reasons and advice to future generations associated with a sustainable option choice [11]. Second, IA might have functioned as a one-way communication device for the current generation to have a legacy motive of being a cooperation initiator or successor, giving an opportunity of receiving and sending generations' decisions with reasons and advice [85,118-120]. Third, IA might have triggered people to have a moral commitment across generations in the sense that being accountable is known to signify fairness and/or justice concerns in people's judgment and decisions [86,87,121]. Thompson [10] and MacKenzie [11] also argue that children and/or future generations are main subjects of such a moral commitment.

The literature suggests that deliberative democratic innovations, such as mini-publics and citizens' assemblies, can address IS and the underrepresentation of some groups in indirect democracy $[23,25,27,67,68,88-90,122,123]$. Only a few studies have conducted experiments with mixed models for the effect of deliberation on IS, establishing that people sacrifice themselves today for their future benefits [3,57]. IS problems are considered to reflect a variety of real-life daily decisions. A person, people and/or societies must choose between unsustainable and sustainable options where generations are biologically and socially connected, for example, buying biodegradable or plastic products, using environmentally-friendly or fossil-fuel transportation, adopting nonrenewable or renewable energies, and so on. In this type of IS problem, the choices shall unidirectionally affect future generations including those who are not born yet. Our experiments are conducted in an environment where generations are biologically and socially disconnected under a non-overlapping setting, showing the positive effects of deliberation and accountability on IS dilemma problems. Therefore, the experimental results can be considered to confirm an existence of the positive effect in a more harsh (disconnected) environment than 
a real (connected) one, being interpreted that deliberation and accountability for future generations bring a possibility for people to choose and/or support a sustainable option in real-world IS problems with two deliberative forms of democracy in mixed models. In this sense, this research contributes to the literature on democratic innovations in a class of mixed models [3,47], and demonstrates experimentally that deliberation and/or accountability lead people to enhance IS (or to resolve the underrepresentation problem of future generations) even in such a harsh environment.

Nearly $60 \%$ of the countries and four billion people of the world have adopted democratic institutions in the last century [124]. Most of these democratic countries and populations rely on anonymous voting to make important social or political decisions that have future consequences for the subsequent generations without requiring deliberation and accountability. Importantly, it is very likely that societies and countries will continue voting as a democratic mechanism in future [125]. In the real world, however, there are several examples of deliberation and accountability practices (see $[23,25,59,88,89]$ ). Some mini-publics, local assemblies (called "gram shabhas") and ad hoc committees are reported to be successful in development activities by introducing deliberation practices in collective decision-making, materializing their social goals [13,23,61,62,126-128]. Wales has attempted to institutionalize public accountability for future generations' wellbeing that can be considered one example of accountability practices in public policy $[129,130]$. To resolve not only for the IS, but also for the underrepresentation problem of future generations, it shall be necessary to institutionalize deliberation and accountability, as far as democracy remains as a main form of political systems. Although it would be challenging to implement large-scale deliberative and accountability processes, there are several advanced technologies that could enable this, such as social media and online platforms [20,22]. It is our belief that deliberation and accountability are integral elements for human societies to transition to be sustainable, and it shall be possible when technologies are integrated with democratic systems.

Finally, we note some limitations and possibilities for future research. First, we should not overlook that generations fail in ensuring high levels of IS under three models of decision-making, implying that some drastic change or new forms of social institutions along with democracy may be necessary as discussed in the literature $[15,19,31,32,131]$. Second, we only consider direct democracy as experimental treatments in this research. However, in the contemporary world, representative (or indirect) democracy is popular. It is important to examine IS under some forms of indirect democracy in the future. Third, as posited by Habermas, the deliberation in our experiment does not satisfy the "ideal speech" condition $[51,53]$, and the number of generation members is limited to be three. Future studies should be able to investigate IS by extending the deliberation conditions, such as the number of generation members. Fourth, this study includes only Japanese students from the student subject pool of KUT so that the effects of treatments can be underestimated. Future studies in this domain should examine IS by taking subjects from a general public pool for external validity. These caveats notwithstanding, we believe that this work is an essential step as experimental research, suggesting how two forms of deliberative democracy can enhance IS and represent potential interests of future generations.

Supplementary Materials: The following are available at https:/ /www.mdpi.com/article/10.3390/ su13137377/s1.

Author Contributions: Conceptualization, P.K., R.R.T. and K.K.; Data curation, P.K.; Formal analysis, P.K., R.R.T. and K.K.; Funding acquisition, K.K.; Investigation, P.K., R.R.T. and K.K.; Methodology, P.K., R.R.T. and K.K.; Project administration, P.K., R.R.T. and K.K.; Resources, P.K., R.R.T. and K.K. and K.K. ; Software, P.K., R.R.T. and K.K.; Supervision, K.K.; Validation, K.K.; Visualization, P.K., R.R.T. and K.K.; Writing—original draft, P.K., R.R.T. and K.K.; Writing-review and editing, P.K., R.R.T. and K.K. All authors have read and agreed to the published version of the manuscript.

Funding: The authors are grateful to the Grant-in-Aid for Japan Society for the Promotion of Science (16H03621) and Kochi University of Technology. 
Institutional Review Board Statement: The study was conducted according to the guidelines of the Declaration of Helsinki, and approved by the Institutional Review Board (or Ethics Committee) of Kochi University of Technology (protocol code: 38-C2 and date of approval: 1 April 2016).

Informed Consent Statement: Informed consent was obtained from all subjects involved in the study. Data Availability Statement: Not applicable.

Acknowledgments: We would like to thank the anonymous referees, Makoto Kakinaka, Hiroaki Miyamoto, Kenta Tanaka, Yoshinori Nakagawa, Yoichi Hizen, Junichi Hirose, Jingchao Zhang, Mostafa Shahen, Shibly Shahrier, Yayan Hernuryadin, Moinul Islam, Asma Khatun, Kostya Ovsiannikov and Arpana Pandit for suggestions and/or supports. The authors specially thank Yuki Yanai for valuable comments and advice. The authors appreciate Koki Tanabe and research assistants for technical supports in implementing the experiments.

Conflicts of Interest: The authors declare no conflict of interest.

\section{References}

1. Przeworski, A.; Stokes, S.; Manin, B. Democracy, Accountability and Representation, Volume 2; Cambridge University Press: Cambridge, UK, 2012.

2. Fiorino, D. Can Democracy Handle Climate Change? Polity Press: Cambridge, UK, 2018.

3. MacKenzie, M.; Caluwaerts, D. Paying for the future: Deliberation and support for climate action policies. J. Environ. Policy Plan. 2021, forthcoming.

4. Shearman, D.; Smith, J. The Climate Change Challenge and the Failure of Democracy; Praeger Publishers: Westpost, CT, USA, 2007.

5. Gonzalez-Ricoy, I.; Gosseries, A. Institutions for Future Generations; Oxford University Press: Oxford, UK, 2016.

6. Hansen, G.; Imrohoroglu, S. Fiscal reform and government debt in Japan: A neoclassical perspective. Rev. Econ. Dyn. 2016, 21, 201-224. [CrossRef]

7. Steffen, W.; Rockstrom, J.; Richardson, K.; Lenton, T.; Folke, C.; Liverman, D.; Summerhayes, C.; Barnosky, A.; Cornell, S.; Crucifix, M.; et al. Trajectories of the Earth system in the anthropocene. Proc. Natl. Acad. Sci. USA 2018, 115, 8252-8259. [CrossRef] [PubMed]

8. Caney, S. Justice and future generations. Annu. Rev. Political Sci. 2018, 21, 475-493. [CrossRef]

9. Bamber, J.; Oppenheimer, M.; Kopp, R.; Aspinall, W.; Cooke, R. Ice sheet contributions to future sea-level rise from structured expert judgment. Proc. Natl. Acad. Sci. USA 2019, 116, 11195-11200. [CrossRef] [PubMed]

10. Thompson, D. Representing future generations: Political presentism and democratic trusteeship. Crit. Rev. Int. Soc. Political Philos. 2010, 13, 17-37. [CrossRef]

11. MacKenzie, M. Deliberation and long-term decisions: Representing future generations. In The Oxford Handbook of Deliberative Democracy; Oxford University Press: Oxford, UK, 2018; pp. 1-31.

12. Smith, G. Deliberative Democracy and the Environment; Routledge: London, UK, 2003.

13. MacKenzie, M.; O’Doherty, K. Deliberating future issues: Minipublics and salmon genomics. J. Public Delib. 2011, 7, 1-27. [CrossRef]

14. MacKenzie, M. Institutional design and sources of short-termism. In Institutions for Future Generations; Oxford University Press: Oxford, UK, 2016; pp. 24-47.

15. Saijo, T. Future design: Bequeathing sustainable natural environments and sustainable societies to future generations. Sustainability 2020, 12, 6467. [CrossRef]

16. Jacobs, A.; Matthews, J. Why do citizens discount the future? Public opinion and the timing of policy consequences. Br. J. Political Sci. 2012, 42, 903-935. [CrossRef]

17. List, C.; Luskin, R.; Fishkin, J.; McLean, I. Deliberation, single-peakedness, and the possibility of meaningful democracy: Evidence from deliberative polls. J. Politics 2013, 75, 80-95. [CrossRef]

18. Mansbridge, J. Rethinking representation. Am. Political Sci. Rev. 2003, 97, 515-528. [CrossRef]

19. Bogacki, J.; Letmathe, P. Representatives of future generations as promoters of sustainability in corporate decision processes. Bus. Strategy Environ. 2021, 30, 1-15. [CrossRef]

20. Strandberg, K. Public deliberation goes on-line? Javnost Public 2008, 15, 71-89. [CrossRef]

21. Fishkin, J. When the People Speak: Deliberative Democracy and Public Consultation; Oxford University Press: Oxford, UK, 2009.

22. Gronlund, K.; Strandberg, K.; Himmelroos, S. The challenge of deliberative democracy online-A comparison of face-to-face and virtual experiments in citizen deliberation. Inf. Polity 2009, 14, 187-201. [CrossRef]

23. Geissel, B.; Newton, K. Evaluating Democratic Innovations; Routledge: New York, NY, USA, 2012.

24. Dangelico, R.; Pontrandolfo, P. Being 'green and competitive': The impact of environmental actions and collaborations on firm performance. Bus. Strategy Environ. 2013, 24, 413-430. [CrossRef]

25. Stoiciu, V.; Gherghina, S. Intra-party deliberation, under-represented groups, and candidate selection: The case of demos in Romania. Political Stud. Rev. 2021, 19, 179-185. [CrossRef] 
26. Shahen, M.; Kotani, K.; Saijo, T. Intergenerational sustainability is enhanced by taking the perspective of future generations. Sci. Rep. 2021, 11, 2437. [CrossRef]

27. Elstub, S.; Escobar, O. Handbook of Democratic Innovation and Governance; Edward Elgar Publishing: Cheltenham, UK, 2019.

28. Allegretti, G. Participatory democracies: A slow march toward new paradigms from Brazil to Europe? In Cities into the Future; Les Classiques des Sciences Sociales: Chicoutimi, QC, Canada, 2014.

29. Pickering, J.; Backstrand, K.; Schlosberg, D. Between environmental and ecological democracy: Theory and practice at the democracy-environment nexus. J. Environ. Policy Plan. 2020, 22, 1-15. [CrossRef]

30. Gronlund, K.; Setala, M.; Herne, K. Deliberation and civic virtue: Lessons from a citizen deliberation experiment. Eur. Political Sci. Rev. 2010, 2, 95-117. [CrossRef]

31. Kamijo, Y.; Komiya, A.; Mifune, N.; Saijo, T. Negotiating with the future: Incorporating imaginary future generations into negotiations. Sustain. Sci. 2017, 12, 409-420. [CrossRef]

32. Shahrier, S.; Kotani, K.; Saijo, T. Intergenerational sustainability dilemma and the degree of capitalism in societies: A field experiment. Sustain. Sci. 2017, 12, 957-967. [CrossRef]

33. Levitt, S.; List, J. What do laboratory experiments measuring social preferences reveal about the real world? J. Econ. Perspect. 2007, 21, 153-174. [CrossRef]

34. Alatas, V.; Cameron, L.; Chaudhuri, A.; Erkal, N.; Gangadharan, L. Subject pool effects in a corruption experiment: A comparison of Indonesian public servants and Indonesian students. Exp. Econ. 2008, 12, 113-132. [CrossRef]

35. Roe, B.; Just, D. Internal and external validity in economics research: Tradeoff's between experiments, filed experiments, natural experiments, and field data. Am. J. Agric. Econ. 2009, 91, 1266-1271. [CrossRef]

36. Falk, A.; Heckman, J. Lab experiments are a major source of knowledge in the social sciences. Science 2009, 326, 535-538. [CrossRef] [PubMed]

37. May, J. Defining democracy: A bid for coherence and consensus. Political Stud. 1978, 26, 1-14. [CrossRef]

38. Elliott, J. Joseph A. Schumpeter and the theory of democracy. Rev. Soc. Econ. 1994, 52, 280-300. [CrossRef]

39. Dahl, R. On Democracy; Yale University Press: New Haven, CT, USA, 2015.

40. Diamond, L.; Plattner, M. Electoral Systems and Democracy; The Johns Hopkins University Press: Baltimore, MD, USA, 2006.

41. Warren, M. A problem-based approach to democratic theory. Am. Political Sci. Rev. 2017, 111, 39-53. [CrossRef]

42. Haas, M. Why Democracies Flounder and Fail; Springer International Publishing: Berlin/Heidelberg, Germany, 2019.

43. Austen-Smith, D.; Banks, J. Information aggregation, rationality, and the condorcet jury theorem. Am. Political Sci. Rev. 1996, 90, 34-45. [CrossRef]

44. Austen-smith, D.; Feddersen, T. Deliberation, preference uncertainty, and voting rules. Am. Political Sci. Rev. 2006, 100, 209-217. [CrossRef]

45. Jackson, M.; Tan, X. Deliberation, disclosure of information, and voting. J. Econ. Theory 2013, 148, 2-30. [CrossRef]

46. List, C. Democratic deliberation and social choice: A review. In The Oxford Handbook of Deliberative Democracy; Oxford University Press: Oxford, UK, 2018; pp. 497-538.

47. Perote-Pena, J.; Piggins, A. A model of deliberative and aggregative democracy. Econ. Philos. 2015, 31, 93-121. [CrossRef]

48. Estlund, D. Democratic Authority: A Philosophical Framework; Princeton University Press: Princeton, NJ, USA, 2009.

49. Mercier, H.; Landemore, H. Reasoning is for arguing: Understanding the successes and failures of deliberation. Political Psychol. 2012, 33, 243-258. [CrossRef]

50. Landemore, H. Democratic Reason: Politics, Collective Intellengence and Rule of Many; Princetion University Press: Princeton, NJ, USA, 2013.

51. Habermas, J. The Theory of Communicative Action, Volume 1: Reason and the Rationalization of Society; The MIT Press: Cambridge, MA, USA, 1984.

52. Elster, J. The market and the forum: Three varieties of political theory. In Deliberative Democracy: Essays on Reasons and Politics; The MIT Press: Cambridge, MA, USA, 1997; pp. 3-34.

53. Habermas, J. Three normative models of democracy. Constellations 1994, 1, 1-10. [CrossRef]

54. Chambers, S. Deliberative democratic theory. Annu. Rev. Political Sci. 2003, 6, 307-326. [CrossRef]

55. Delli Carpini, M.; Cook, F.; Jacobs, L. Public deliberation, discursive participation, and citizen engagement: A review of the empirical literature. Annu. Rev. Political Sci. 2004, 7, 315-344. [CrossRef]

56. Mansbridge, J.; Bohman, J.; Chambers, S.; Estlund, D.; Follesdal, A.; Fung, A.; Lafont, C.; Manin, B.; Matri, J. The place of self-interest and the role of power in deliberative democracy. J. Political Philos. 2010, 18, 64-100. [CrossRef]

57. Dietz, T.; Stern, P.; Dan, A. How deliberation affects stated willingness to pay for mitigation of carbon dioxide emissions: An experiment. Land Econ. 2009, 85, 329-347. [CrossRef]

58. Goeree, J.; Yariv, L. An experimental study of collective deliberation. Econometrica 2011, 79, 893-921.

59. Gherghina, S.; Geissel, B. Linking democratic preferences and political participation: Evidence from Germany. Political Stud. 2017, 65, 24-42. [CrossRef]

60. Gherghina, S.; Geissel, B. Support for direct and deliberative models of democracy in the UK: Understanding the difference. Political Res. Exch. 2020, 2, 1809474. [CrossRef]

61. Setala, M. Connecting deliberative mini-publics to representative decision making. Eur. J. Political Res. 2017, 56, 846-863. [CrossRef] 
62. Setala, M.; Christensen, H.; Leino, M.; Strandberg, K.; Back, M.; Jaske, M. Deliberative mini-publics facilitating voter knowledge and judgement: Experience from a Finnish local referendum. Representation 2021, forthcoming.

63. Luskin, R.; Fishkin, J.; Jowell, R. Considered opinions: Deliberative polling in Britain. Br. J. Political Sci. 2002, 32, $455-487$. [CrossRef]

64. Simon, A.; Sulkin, T. Discussion's impact on political allocations: An experimental approach. Political Anal. 2002, 10, 403-412. [CrossRef]

65. Persson, M.; Esaiasson, P.; Gilljam, M. The effects of direct voting and deliberation on legitimacy beliefs: An experimental study of small group decision-making. Eur. Political Sci. Rev. 2012, 5, 381-399. [CrossRef]

66. Habermas, J. Between Facts and Norms: Contributions to a Discourse Theory of Law and Democracy; The MIT Press: Cambridge, MA, USA, 1996.

67. Caluwaerts, D.; Reuchamps, M. The Legitimacy of Citizen-Led Deliberative Democracy: The G1000 in Belgium; Routledge: London, UK, 2020.

68. Harris, C. Looking to the Future: Including Children, Young People and Future Generations in Deliberations on Climate Action. 2021. Available online: https:/ / constdelib.com/wp-content/uploads/2021/05/WP11-2021-CA17135.pdf (accessed on 30 June 2021).

69. Dalton, R.; Burklin, W.; Drummond, A. Public opinion and direct democracy. J. Democr. 2001, 12, 141-153. [CrossRef]

70. Jeydel, A.; Steel, B. Public attitudes toward the initiative process in Oregon. State Local Gov. Rev. 2002, 34, 173-182. [CrossRef]

71. Barbosa, S. COMUNIX WhatsAppers: The community school in Portugal and Spain. Political Stud. Rev. 2021, 19, 171-178. [CrossRef]

72. Fischer, M.; Irlenbusch, B.; Sadrieh, A. An intergenerational common pool resource experiment. J. Environ. Econ. Manag. 2004, 48, 811-836. [CrossRef]

73. Setala, M.; Gronlund, K.; Herne, K. Citizen deliberation on nuclear power: A comparison of two decision-making methods. Political Stud. 2010, 58, 688-714. [CrossRef]

74. Himmelroos, S.; Christensen, H. Deliberation and opinion change: Evidence from a deliberative mini-public in Finland. Scand. Political Stud. 2013, 37, 41-60. [CrossRef]

75. Hauser, O.; Rand, D.; Peysakhovich, A.; Nowak, M. Cooperating with the future. Nature 2014, 511, 220-223. [CrossRef] [PubMed]

76. Sherstyuk, K.; Tarui, N.; Ravago, M.; Saijo, T. Intergenerational games with dynamic externalities and climate change experiments. J. Assoc. Environ. Resour. Econ. 2016, 3, 247-281. [CrossRef]

77. Fochmann, M.; Sachs, F.; Sadrieh, A.; Weimann, J. The two sides of public debt: Intergenerational altruism and burden shifting. PLoS ONE 2018, 13, e0202963. [CrossRef] [PubMed]

78. Kamijo, Y.; Hizen, Y.; Saijo, T.; Tamura, T. Voting on behalf of a future generation: A laboratory experiment. Sustainability 2019, 11, 4271. [CrossRef]

79. Nakagawa, Y.; Kotani, K.; Matsumoto, M.; Saijo, T. Intergenerational retrospective viewpoints and individual policy preferences for future: A deliberative experiment for forest management. Futures 2019, 105, 40-53. [CrossRef]

80. Dryzek, J.; Niemeyer, S. Deliberative democracy and climate governance. Nat. Hum. Behav. 2019, 3, 411-413. [CrossRef]

81. Katsuki, S.; Hizen, Y. Does voting solve the intergenerational sustainability dilemma? Sustainability 2020, 12, 6311. [CrossRef]

82. Pandit, A.; Nakagawa, Y.; Timilsina, R.; Kotani, K.; Saijo, T. Taking the perspectives of future generations as an effective method for achieving sustainable waste management. Sustain. Prod. Consum. 2021, 27, 1526-1536. [CrossRef]

83. Timilsina, R.; Kotani, K.; Nakagawa, Y.; Saijo, T. Concerns for future generations in societies: A deliberative analysis of the intergenerational sustainability dilemma. J. Behav. Exp. Econ. 2021, 90, 101628. [CrossRef]

84. Shahrier, S.; Kotani, K.; Saijo, T. Intergenerational Sustainability Dilemma and a Potential Solution: Future Ahead and Back Mechanism; Working Paper SDES-2017-9; Research Institute for Future Design, Kochi University of Technology: Kochi, Japan, 2017.

85. Timilsina, R.; Kotani, K.; Nakagawa, Y.; Saijo, T. Accountability as a Resolution for Intergenerational Sustainability; SDES-2019-2; Research Institute for Future Design, Kochi University of Technology: Kochi, Japan, 2019.

86. Tetlock, P. Accountability and the preseverance of first impressions. Soc. Psychol. Q. 1983, 46, 285-292. [CrossRef]

87. Tetlock, P. Accountability: A social check on the fundamental attribution error. Soc. Psychol. Q. 1985, 85, 227-236. [CrossRef]

88. Vodova, P.; Voda, P. The effects of deliberation in Czech Pirate Party: The case of coalition formation in Borno (2018). Eur. Political Sci. 2020, 19, 181-189. [CrossRef]

89. Gad, N. A "new political culture": The challenges of deliberation in Alternativet. Eur. Political Sci. 2020, 19, 190-199. [CrossRef]

90. Gherghina, S.; Stoiciu, V. Selecting candidates through deliberation: The effects for Demos in Romania. Eur. Political Sci. 2020, 19, 171-180. [CrossRef]

91. Tzoumis, K.; Finegold, L. Looking at the quality of draft environmental impact statements over time in the United States. Environ. Impact Assess. Rev. 2000, 20, 557-578. [CrossRef]

92. Glasson, J.; Therivel, R.; Chadwick, A. Introduction to Environmental Impact Assessment, 3rd ed.; Routledge: London, UK, 2005.

93. McKelvey, R.; Palfrey, T. An experimental study of the centipede game. Econometrica 1992, 60, 803-836. [CrossRef]

94. Binmore, K. Game Theory and the Social Contract, Volume 1: Playing Fair; The MIT Press: Cambridge, MA, USA, 1994.

95. Ochs, J. Games with unique, mixed strategy equilibria: An experimental study. Games Econ. Behav. 1995, 10, 202-217. [CrossRef]

96. Goeree, J.; Holt, C. Stochastic game theory: For playing games, not just for doing theory. Proc. Natl. Acad. Sci. USA 1999, 96, 10564-10567. [CrossRef] [PubMed] 
97. Charness, G.; Rabin, M. Understanding social preferences with simple tests. Q. J. Econ. 2002, 117, 817-869. [CrossRef]

98. Holt, C.; Roth, A. The Nash equilibrium: A perspective. Proc. Natl. Acad. Sci. USA 2004, 101, 3999-4002. [CrossRef] [PubMed]

99. Garcia-Pola, B.; Iriberri, N.; Kovarik, J. Non-equilibrium play in centipede games. Games Econ. Behav. 2020, 120, 391-433. [CrossRef]

100. Belot, M.; Duch, R.; Miller, L. A comprehensive comparison of students and non-students in classic experimental games. J. Econ. Behav. Organ. 2015, 113, 26-33. [CrossRef]

101. Frechette, G. Laboratory experiments: Professionals versus students. In Handbook of Experimental Economic Methodology; Oxford University Press: New York, NY, USA, 2015.

102. Nguyen, K. Formal versus informal system to mitigate non-point source pollution: An experimental investigation. J. Agric. Econ. 2020, 71, 838-852. [CrossRef]

103. Murphy, R.; Ackermann, K.; Handgraaf, M. Measuring social value orientation. Judgement Decis. Mak. 2011, 6, 771-781. [CrossRef]

104. Van Lange, P.; Bekkers, R.; Schuyt, T.; Vugt, M. From games to giving: Social value orientation predicts donations to noble causes. Basic Appl. Soc. Psychol. 2007, 29, 375-384. [CrossRef]

105. Brosig-Koch, J.; Helbach, C.; Ockenfels, A.; Weimann, J. Still different after all these years: Solidarity behavior in East and West Germany. J. Public Econ. 2011, 95, 1373-1376. [CrossRef]

106. Croson, R.; Gneezy, U. Gender differences in preferences. J. Econ. Lit. 2009, 47, 448-474. [CrossRef]

107. Angrist, J.; Pischke, J. Mostly Harmless Econometrics: An Empiricist's Companion; Princeton University Press: Princeton, NJ, USA, 2009.

108. Timilsina, R.; Kotani, K.; Kamijo, Y. Sustainability of common pool resources. PLoS ONE 2017, 12, e0170981. [CrossRef]

109. Inoue, Y.; Himichi, T.; Mifune, N.; Saijo, T. People prefer joint outcome prosocial resource distribution towards future others. Sci. Rep. 2021, 11, 5373. [CrossRef] [PubMed]

110. Kirman, A.; Teschl, M. Selfish or selfless? The role of empathy in economics. Philos. Trans. R. Soc. B Biol. Sci. 2010, 365, 303-317. [CrossRef] [PubMed]

111. Artinger, F.; Exadaktylos, F.; Koppel, H.; Saaksvuori, L. In others' shoes: Do individual differences in empathy and theory of mind shape social preferences? PLoS ONE 2014, 9, e92844. [CrossRef]

112. Font, X.; Garay, L.; Jones, S. A social cognitive theory of sustainability empathy. Ann. Tour. Res. 2016, 58, 65-80. [CrossRef]

113. Sapolksy, R. Behave: The Biology of Humans at Our Best and Worst; Penguin Press: New York, NY, USA, 2017.

114. Pettit, P.; Rabinowicz, W. Deliberative democracy and the discursive dilemma. Philos. Issues 2001, 11, 268-299. [CrossRef]

115. List, C. The discursive dilemma and public reason. Ethics 2006, 116, 362-402. [CrossRef]

116. Charness, G.; Dufwenberg, M. Promises and partnership. Econometrica 2006, 74, 1579-1601. [CrossRef]

117. Fox, M.; Tost, L.; Wade-Benzoni, K. The legacy motive: A catalyst for sustainable decision-making in organizations. Bus. Ethics Q. 2010, 20, 153-185. [CrossRef]

118. Wade-Benzoni, K. Legacy motivations \& the psychology of intergenerational decisions. Curr. Opin. Psychol. 2019, 26, 19-22.

119. Kotre, J. Outliving the Self: Generativity an the Interpretation of Lives; The Johns Hopkins University Press: Baltimore, MD, USA, 1996.

120. Kotre, J. Make It Count: How to Generate a Legacy That Gives Meaning to Your Life; Free Press: New York, NY, USA, 1999.

121. Self, W.; Mitchell, G.; Mellers, B.; Tetlock, P.; Hildreth, A. Balancing fairness and efficiency: The impact of identity-blind and identity-conscious accountability on applicant screening. PLoS ONE 2015, 10, e0145208. [CrossRef] [PubMed]

122. Gherghina, S.; Soare, S.; Jacquet, V. Deliberative democracy and political parties: Functions and consequences. Eur. Political Sci. 2020, 19, 200-211. [CrossRef]

123. Gherghina, S.; Mokre, M.; Miscoiu, S. Introduction: Democratic deliberation and under-represented groups. Political Stud. Rev. 2020. [CrossRef]

124. Roser, M. Democracy. Our World in Data. 2018. Available online: https://ourworldindata.org/democracy (accessed on 20 December 2020).

125. Hill, L. Deliberative democracy and compulsory voting. Elect. Law J. Rules Politics Policy 2013, 12, 454-467. [CrossRef]

126. Ban, R.; Jha, S.; Rao, V. Who has voice in a deliberative democracy? Evidence from transcripts of village parliaments in South India. J. Dev. Econ. 2012, 99, 428-438. [CrossRef]

127. Warren, M.; Gastil, J. Can deliberative Minipublics address the cognitive challenges of democratic citizenship? J. Politics 2015, 77, 562-574. [CrossRef]

128. Parthasarathy, R.; Rai, V. Deliberative Democracy in India; Policy Research Working Paper Series 7995; World Bank: Washington, DC, USA, 2017.

129. Davies, H. The well-being of future generations Wales Act 2015: Duties or aspirations? Environ. Law Rev. 2016, 18, 41-56. [CrossRef]

130. Davies, H. The well-being of future generations Wales Act 2015-A step change in the legal protection of the interests of future generations? J. Environ. Law 2017, 29, 165-175. [CrossRef]

131. Saijo, T. Future design. In The Future of Economic Design; Springer International Publishing: Berlin/Heidelberg, Germany, 2019; pp. 253-260. 